\title{
PENGARUH PENGGUNAAN MEDIAL ARCH SUPPORT TERHADAP PENURUNAN DERAJAT FLAT FOOT PADA ANAK USIA 8 - 12 TAHUN
}

\author{
Prasetyo Catur Utomo, Dwi Setyawan, Muhammad Fathi \\ Kementerian Kesehatan Politeknik Kesehatan Surakarta Jurusan Ortotik Prostetik \\ Diterima : 2 Oktober 2018, Disetujui : 9 Oktober 2018 \\ e-mail : prasetyo_catur@yahoo.com,
}

\begin{abstract}
Background: The World Health Organization (WHO) provides evidence that there are hundreds of millions of people affected by life due to musculoskeletal disorders. Musculoskeletal disorders that are often found are flat foot or commonly called flat foot. In the treatment of flat foot, prosthetic orthotics can provide orthosis services in the form of medial arch support with sponge and plastic material, which aims to provide support to the plantaris area of the foot and restore the shape of the arch to the foot. Method: This type of research is Quasi Experiment with two groups design Pre Test and Post Test Design. The population in this study included students of grades 2-6 at SDN Gagaksipat 1, Ngemplak, Boyolali, Central Java. The number of samples is 28 students. Data collection techniques using the wetfootprint pre test and post test. Results : There is an effect of using medial arch support on the reduction of flatfoot degrees. These results can be seen from the results of Wilcoxon test, which is known below the $p$ value $=0,000$. Then if the value of $p<0.05$. Conclusion: It can be concluded that there is an effect of medial use arh support for decreasing flatfoot degrees in children aged 8-12 years. From the results of the study it was found that there were 28 research samples that experienced a decrease in the degree of flatfoot.
\end{abstract}

Keywords: Flat Foot, Medial Arch Support

\section{PENDAHULUAN}

Seiring berjalannya waktu dan perkembangan zaman yang makin maju banyak masalah juga yang ditemui, salah satunya adalah masalah dalam bidang kesehatan. Gangguan kesehatan yang banyak dialami salah satunya adalah gangguan pada musculoskeletal. Gangguan musculoskeletal dapat menyerang siapa saja mulai dari saat lahir sampai dewasa. World Health Organization (WHO) memberikan peryantaan bahwa terdapat ratusan juta orang terganggu kehidupan akibat gangguan musculoskeletal. Gangguan musculoskeletal yang banyak dijumpai adalah kaki datar atau yang biasa disebut flat foot. Menurut Evans sekitar 20-30\% dari seluruh anak di dunia mengalami flat foot dan menurut Pande ketut, sekitar $18 \%$ atau 6 dari 33 anak memiliki kecenderungan flat foothasil ini diperoleh dari hasil survey yang dilakukan di SDN Coblong 2 Bandung. (Wardanie, 2013).

Prevalensi flat foot pada kelompok anak berusia 3 tahun adalah sebesar 54\% dan pada kelompok anak berusia 6 tahun sebesar 24\%. Sebagian besar anak akan menunjukkan perkembangan normal dari telapak kaki secara utuh pada usia 10 tahun (Rodriguez, 1999). Flat foot diakibatkan dari ligament yang terlalu lemah, hilangnya tenaga otot yang menstabilkan yaitu otot tibialis posterior, 
distribusi beban yang abnormal atau kombinasi dari faktor- faktor itu. Penyebab yang mendasari sering diturunkan, karena itu kelainan ini sering ditemukan pada orang - orang dari satu keluarga (Apley, 1995). Kelainan flat foot dalam jangka panjang akan menyebabkan nyeri pada telapak kaki, pergelangan kaki dan lutut, selalin itu juga akan menyebabkan trauma akut yang berulang hingga terjadinya deformitas pada kaki (Wardanie, 2013).

Apabila kaki datar diderita maka seseorang individu tidak saja sukar berjalan, tetapi juga mengalami masalah keseimbangan badan, kajian yang dilakukan di Taiwan didapatkan, 8700 individu dewasa berumur 30 tahun ke atas mengalami berbagai masalah akibat komplikasi pada kaki. Ini terjadi karena kelainan pada kaki merusak secara perlahan-lahan dan keluhan baru akan muncul ketika 5-10 tahun, tidak semua kondisi flat foot menyebabkan seseorang mengalami masalah gangguan keseimbangan karena secara fisiologis keseimbangan tubuh anak-anak ditentukan oleh fungsi neurologis sistem otak dan sistem vestibular (alat keseimbangan), yang mana pada kelompok siswa ini kedua fungsi tersebut berkembang normal. Disamping itu, anak-anak telah melakukan permainan-permainan yang memerlukan keseimbangan tubuh sejak masa taman kanak-kanak (Lendra, 2009).

Ortotik Prostetik merupakan upaya pelayanan kesehatan profesional, yang bertanggung jawab atas kesehatan klien yang mengalami deformitas, dengan mem-berikan layanan berupa (1) pembuatan ortosis yang meliputi alat bantu aktivitas anggota gerak atas/ mobilitas anggota gerak bawah, dan pembuatan alat penguat/penyangga tubuh,
(2) pembuatan prostesis yaitu alat pengganti anggota gerak tubuh yang hilang (Profile, 2007). Ortosis adalah alat bantu kesehatan yang berfungsi untuk bracing, splinting, dan supporting yang dipasangkan di luar tubuh yang diperuntukkan bagi pasien atau klien yang membutuhkan (Permenkes, 2013). Pada penanganan flat foot, ortotik prostetik dapat memberikan pelayanan ortosis berupa medial arch support dengan bahan spon dan plastik, yang bertujuan untuk memberikan support pada daerah plantaris kaki dan mengembalikan bentuk lengkungan pada kaki. Berdasarkan hal itulah maka tujuan dari penelitian ini adalah untuk meng-etahui pengaruh penggunaan medial archsupport terhadap pengurangan derajat flatfoot.

Anatomi Kaki dan pergelangan kaki dalam tubuh manusia bekerja sama untuk memberikan keseimbangan , stabilitas, gerakan, dan propulsi. Struktur komplek anatomi dari kaki terdiri dari 26 tulang, 33 sendi, otot, ligamen, tendon, saraf, pembuluh darah dan jaringan lunak. (Ghadiali, 2013).

Integritas kaki dipertahankan oleh dua arkus longitudinal (medialis dan lateralis) dan satu arkus transversal. Semua arkus ini dipersatuakan oleh kombinasi faktor-faktor tulang, ligamentum, dan muskular sehingga berat badan saat berdiri ditahan oleh bagian posterior calcaneus dan kaput metatarsal akibat integritas arkus.

Flat foot adalah kelainan kompleks yang sering terjadi dan sering ditemui dilahan, dengan bermacam-macam gejala dengan derajat deformitas dan disability yang bermacam- macam, ada beberapa tipe kaki datar yang semuanya dilihat dari keadaan arkus yang hilang baik sebagian maupun keseluruhan. Arkus adalah celah 
antara bagian dalam dari kaki dan permukaan tanah, kaki datar adalah kondisi dimana kaki tidak memiliki lengkungan telapak kaki yang normal, kondisi ini bisa mengenai satu atau kedua kaki, seseorang dengan arkus rendah atau tidak memiliki arkus biasanya mengarah untuk kondisi yang disebut kaki datar (Flat feet, atau fallen arches). Ciri-ciri klinis yang utama dari pronasi yang berlebihan. Kaki datar memiliki nama lain baik dalam istilah medis maupun istilah asing yaitu pes planus, pes planovalgus, fallen arches, flat foot,pronation of Feet, Excessive Pronation, Talipes Calcaneal Valgus yaitu kondisi dimana lebih banyak permukaan kaki yang menapak pada lantai dibandingkan dengan kaki normal.

\section{METODE PENELITIAN}

Jenis penelitian ini adalah Quasi Experiment dengan rancangan two group Pre Test and Post Test Design. Populasi dalam penelitian ini meliputi siswa/siswi kelas 2-6 di SDN Gagaksipat 1, Ngemplak, Boyolali, Jawa Tengah. Teknik sampling yang digunakan dalam penelitian ini adalah purposive sampling. Dengan memberikan inklusi dan ekslusi untuk pengambilan sample penelitian. Jumlah sample yang didapatkan sebanyak 28 siswa.

Tahap pelaksanaan: pengambilan sampel berdasarkan kriteria inklusi, (2) dilakukan pre test pada Maret 2017 ter-hadap subyek penelitian, untuk meng-etahui flatfoot kemudian dicatat hasilnya. (3) Kepada subyek kelompok perlakuan diinstruksikan untuk menggunakan me-dial arch support dalam waktu 1 bulan. (4) dilakukan post test setelah 1 bulan penggunaan medial arch support.

\section{HASIL PENELITIAN}

Karakteristik subjek penelitian dapat dilihat pada tabel berikut:

Tabel 1. Karakteristik jenis kelamin, umur, jenis flat foot

\begin{tabular}{lll}
\hline Karakteristik & $\mathbf{n}$ & $\mathbf{\%}$ \\
\hline Jenis Kelamin & & \\
Laki-laki & 18 & 64,2 \\
Perempuan & 10 & 35,8 \\
& & \\
Umur & & \\
10 tahun & 10 & 35,7 \\
11 tahun & 10 & 35,7 \\
12 tahun & 8 & 28,6 \\
& & \\
Jenis flatfoot & & \\
Bilateral & 17 & 60,7 \\
Unilateral & 11 & 39,3 \\
\end{tabular}

Untuk mengetahui pengaruh maka dilakukan uji beda. Uji beda ini dilakukan untuk mengetahui perbedaan pengurangan derajat flatfoot sebelum dan sesudah menggunakan medial arch support pada sampel penelitian. Uji beda dilakukan di SPSS dengan menggunakan wilcoxon test. Uji tersebut dilakukan karena distribusi data tidak normal. Sehingga menggunakan uji non parametric wilcoxon test.

Hasil wilcoxon test dapat dilihat di tabel berikut:

Tabel 2. Pretest dan Post test

\begin{tabular}{llll}
\hline Pretest-PostTest & N & $\begin{array}{c}\text { Mean } \\
\text { Rank }\end{array}$ & $\begin{array}{c}\text { Sum of } \\
\text { Rank }\end{array}$ \\
\hline Negative Rank & 32 & 16,50 & 528,00 \\
\hline $\begin{array}{l}\text { Positif Rank } \\
\text { Ties }\end{array}$ & & & \\
$\begin{array}{l}\text { Asymp.Sig. (2- } \\
\text { tailed) }\end{array}$ & 0 & 0,00 &, 00 \\
$\begin{array}{l}\text { Pre-post test }= \\
0.000\end{array}$ & 13 & & \\
\hline \multicolumn{1}{c}{ Dari hasil } & uji wilcoxon di atas
\end{tabular}
diketahui bawah nilai $p=0,000$. Maka jika nilai $\mathrm{p}<0,05$, berarti terdapat pengaruh penggunaan medial arch 
support terhadap pengurangan derajat flatfoot.

Terujinya hipotesis dalam penelitian ini dapat dijelaskan sebagai berikut, flat foot adalah kelainan kompleks yang sering terjadi pada daerah telapak kaki, dengan bermacam-macam gejala dengan derajat deformitas. Secara sederhana kasus flatfoot adalah kondisi dimana telapak kaki datar dan tidak memiliki lengkungan. Untuk menggantikan tugas dan fungsi dari lengkungan ditelapak kaki tersebut maka diberikan alat penyangga berupa medial arch support. Penggunaan medial arch support akan mengembalikan bentuk lengkungan pada medial longitudinal arch. Tujuan dari penggunaan nya adalah agar lengkungan medial longitudinal arch dapat terkoreksi dan tumbuh seperti kaki normal. Dalam penelitian ini sampel penelitian menggunakan medial arch support selama 1 bulan.

\section{PEMBAHASAN}

Berdasarkan derajat flat foot (a). Derajat 1; kaki masih punya arkus meski sangat sedikit. (b). Derajat 2; kaki sudah tak punya arkus sama sekali. (c). Derajat 3; pada derajat ini, kaki tak hanya tidak punya arkus, namun juga terbentuk sudut di pertengahan kaki yang arahnya ke luar
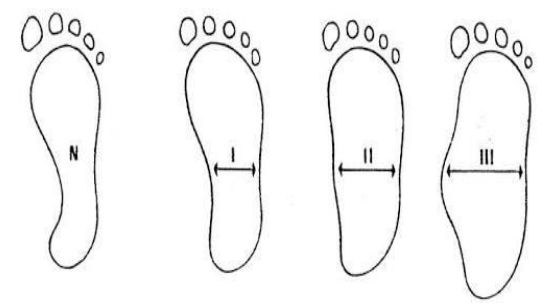

$\mathrm{N}=$ Normal

$1=$ Grade 1

$2=$ Grade 2

$3=$ Grade 3

Gambar 1. Derajat Flat foot (Rodriguez, 1999).

Medial Arch Support adalah jenis ortosis yang di pasang pada bagian medial arkus longitudinalis pedis. Fungsinya adalah sebagai shock breaker tumpuan berat badan pada kaki, untuk support bagian medial arkus longitudinalis pedis dan memberikan stabilitas pada kaki (Nadiaty, 2015). Pemberian medial arch support ini diharapkan arkus longitudinalis pedis menjadi lebih stabil, penumpuan berat badan menjadi lebih normal dan keseimbangan tubuh meningkat dan fungsi berjalan menjadi lebih baik. Penggunaan pada kasus flat foot untuk meningkatkan lengkungan medial longitudinal arch.

Medial arch support ini terbuat dari bahan polimer ringan dan lentur dari bagian heel hingga forefoot. Pada bagian medial terbentuk sebuah tonjolan yang digunakan untuk support arkus pedis pada kaki, sehingga diharapkan dapat menyokong arkus pedis kaki selama digunakan saat berdiri. Medial arch support ini disesuaikan dengan tinggi arkus kaki sehingga akan terasa lebih nyaman dan terjaga keseimbangannya pada saat beraktifitas yaitu saat berdiri. Dengan demikian diharapkan akan meningkatkan stabilitas dan keseimbangan saat berdiri (Nadiaty, 2015).

\section{KESIMPULAN DAN SARAN}

Berdasarkan penelitian yang telah dilakukan, maka dapat disimpulkan bahwa terdapat pengaruh penggunaan medial arh support terhadap penurunan derajat flatfoot pada anak usia 8-12 tahun. Dari hasil penelitian diketahui bahwa terdapat 28 sampel penelitian yang meng-alami penurunan derajat flatfootnya.

Beberapa saran yang dapat dikemukakan dari hasil penelitian ini adalah sebagai berikut : 


\section{Bagi subjek}

Disarankan ketika diketahui terdapat flatfoot di telapak kakinya dalam usia 8-12 tahun, maka disarankan agar menggunakan alat medial archsupport. Sehingga pembentukan archus pada telapak dapat terjadi secara maksimal.

\section{Bagi Peneliti}

Peneliti selanjutnya yang berminat untuk meneliti mengenai pengaruh penggunaan medial arch support disarankan untuk mempertimbangkan faktor dan variabel yang lain.

\section{DAFTAR RUJUKAN}

Apley, A. G (1995). Buku Ajar Ortopedi dan Fraktur sistem Apley. Jakarta: Widya Medika.

Ghadiali, Mufa T (2013). Anatomy Of The Foot And Ankle; Multimedia Health Education.

Lendra, M. D (2009). Beda Pengaruh Kondisi Kaki datar dan kaki dengan arkus terhadap keseimbangan statis pada anak usia 8-12 tahun di kelurahan Karangasem, Surakarta. Jurnal Fisioterapi Vol. 9 No. 2, 49-58.

Rodriguez, A. G (1999). Flexible Flat Feet in Children : A Real Problem? Journal Pediatrics Vol. 103 No.6.

Wardanie, S (2013). Prevalensi Kelainan bentuk kaki (Flat Foot) pada anak usia 6-12 tahun di kota surakarta. 